\title{
COMMENTARY
}

\section{Glycemic control in the critically ill - 3 domains and diabetic status means one size does not fit all!}

\author{
James S Krinsley* \\ See related research by Sechterberger et al., http://ccforum.com/content/17/2/R52, and related research by Krinsley et al., \\ http://ccforum.com/content/17/2/R37
}

\begin{abstract}
Hyperglycemia, hypoglycemia, and increased glucose variability have each been shown to be independently associated with increased risk of mortality in the critically ill. Sechterberger and colleagues have completed a large observational cohort study that demonstrates that diabetic status modulates these relationships in clinically meaningful ways. These findings corroborate, in a strikingly consistent manner, those of another very recently published large observational study.
\end{abstract}

Sechterberger and colleagues [1] recently reported a large single-center observational cohort study of the relationship of diabetic status to dysglycemia - hyperglycemia, hypoglycemia, and increased glycemic variability - and mortality in the critically ill. The online publication of their investigation came less than 2 weeks after that of a nearly identical study that I was privileged to lead and that involved 44,964 patients from 23 intensive care units (ICUs) in four continents [2]. The findings of the two investigations, which both appear in finalized form in this issue of Critical Care, are strikingly similar, a confirmation that strengthens the power of the conclusions of both studies. It may be time to change our glycemic control practice in the ICU - again!

The management of blood glucose (BG) in the critically ill became a topic of great interest following the publication of the landmark single-center surgical ICU study targeting euglyemia ( 80 to $110 \mathrm{mg} / \mathrm{dL}$ ) in Leuven, Belgium, in 2001 [3]. This was truly the 'study that launched a thousand protocols' and resulted in guidelines promoting 'tight' control [4]. Nevertheless, a series of randomized interventional trials targeting euglyemia failed

*Correspondence: james.krinsley@gmail.com

Division of Critical Care, Stamford Hospital and Columbia University College of Physicians and Surgeons, 190 West Broad Street, Stamford, CT 06902, USA to corroborate the impressive findings of the initial study, culminating in the 6,104-patient NICE-SUGAR (Normoglycaemia in Intensive Care Evaluation Survival Using Glucose Algorithm Regulation) trial [5] that suggested that a moderate glycemic target was preferable to 'tighter' control. The pendulum then swung. New guidelines promoted much higher glycemic target ranges (140 to 180 or even 140 to $200 \mathrm{mg} / \mathrm{dL}$ ) for all patients in the ICU [6].

What explains the inconsistent results of the interventional trials of glycemic control in the critically ill? Whereas hyperglycemia was the target of the interventional trials, hypoglycemia was their unifying complication. Hypoglycemia was found to be independently associated with increased risk of mortality in the major interventional trials $[7,8]$ and in several observational cohort studies [9-11]. Glucose variability was not even considered in the design and analysis of the interventional trials. Nevertheless, high levels of this third 'domain' of glycemic control were subsequently found to be independently associated with increased risk of mortality in the Leuven studies [7] and in several retrospective series [12-14]. Finally, the independent role of diabetic status on modulating these relationships has emerged as another crucial factor [15].

The new 'three domains' study by Sechterberger and colleagues [1] evaluated 10,320 patients admitted to a single 24-bed medical-surgical ICU between 2004 and 2011. The target glucose range was initially 72 to $136 \mathrm{mg} /$ dL. After the publication of the NICE-SUGAR trial, the target was changed to 90 to $162 \mathrm{mg} / \mathrm{dL}$. Notably, in keeping with routine clinical practice, the same target was applied to all patients regardless of diagnosis and diabetic status. A U-shaped curve described the relationship of hyperglycemia to mortality among non-diabetics, but there was no consistent relationship between mean BG and mortality among those with diabetes. Hypoglycemia, defined as a BG of not more than $40 \mathrm{mg} / \mathrm{dL}$, was independently associated with increased risk of mortality in both groups, as was 'low glucose', idiosyncratically defined as a BG of 41 to $85 \mathrm{mg} / \mathrm{dL}$. Finally, increasing glycemic variability, defined by using the 
metric of mean absolute glucose change, was independently associated with increased risk of mortality among non-diabetics but not among diabetics. Every one of these major conclusions confirmed the findings of our study, published online by the same journal 11 days earlier [2]!

This convergence has potential implications for clinical practice. The era of 'one size fits all' in regard to glycemic targets in the critically ill has likely ended. In my own ICU, I am preparing my nurses for the task of developing a range of glycemic targets stratified by (a) diagnosis (the earlier study [2], but not the current one [1], evaluated differences between medical and surgical patients), (b) diabetic status, and (c) and among the patients with diabetes, further stratified by the intensity of preadmission glycemic control, based on HgbA1c levels [16]. Perhaps I should make sure I am on vacation on the day that six different protocols are rolled out!

Furthermore, the two 'three domains' studies [1,2] provide a clarion call for the development and clinical implementation of new technologies to monitor BG. Quite simply, intermittent monitoring is not up to the task, a conclusion reached last year by a consensus panel convened at the 32nd International Symposium on Intensive Care and Emergency Medicine [17]. We will be asking our nurses to (a) target a discrete BG range by using insulin, (b) avoid hypoglycemia, and (c) minimize glucose variability. We now have abundant data demonstrating that this cannot be accomplished safely or effectively by using meters, strips, and blood gas analyzers measuring BG at the (Herculean) rate of 13 tests per 24 hours in this study [1] or the three to nine tests per 24 hours (perhaps a more realistic rate, given the 5 to 10 minutes that each measurement takes, from data acquisition to treatment decision) among the centers participating in the earlier study [2]. Moreover, we can be certain that these monitoring frequencies do not detect every episode of dysglyemia that occurs in our patients! Successful management of all three domains of glycemic control will require the use of continuous or nearly continuous technologies [18]. Fortunately, this era is about to begin.

\section{Abbreviations}

BG, blood glucose; ICU, intensive care unit; NICE-SUGAR, Normoglycaemia in Intensive Care Evaluation Survival Using Glucose Algorithm Regulation.

\section{Competing interests}

JSK reported receiving consultant fees from Medtronic Inc. (Minneapolis, MN, USA), Edwards Life Sciences (Irvine, CA, USA), GlySure (Abingdon, UK), Roche Diagnostics (Basel, Switzerland), OptiScan Biomedical (Victoria, Australia), and Alere (San Diego, CA, USA) and research support from OptiScan Biomedical.

Published: 17 April 2013

\section{References}

1. Sechterberger MK, Bosman RJ, Oudemans-van Straaten HM, Siegelaar SE, Hermanides J, Hoekstra JB, Devries JH: The effect of diabetes mellitus on the association between measures of glycemic control and intensive care mortality: a retrospective cohort study. Crit Care 2013, 17:R52.

2. Krinsley JS, Egi M, Kiss A, Amin DN, Schuetz P, Maurer P, Schultz M, van Hooifdonk R, Kiyoshi M, Mackenzie I, Annane D, Stow P, Nasraway S, Holewinski S, Holzinger U, Preiser JC, Vincent JL, Bellomo R: Diabetic status and the relationship of the 3 domains of glycemic control to mortality in critically ill patients: an international multi-center cohort study. Crit Care 2013, 17:R37.

3. Van den Berghe G, Wouters P, Weekers F, Verwaest C, Bruyninckx F, Schetz M, Vlasselaers D, Ferdinande P, Lauwers P, Bouillon R: Intensive insulin therapy in the critically ill patients. N Engl J Med 2001, 345:1359-1367.

4. Garber AJ, Moghissi ES, Bransome ED Jr., Clark NG, Clement S, Cobin RH, Furnary AP, Hirsch IB, Levy P, Roberts R, Van den Berghe G, Zamudio V; American College of Endocrinology Task Force on Inpatient Diabetes Metabolic Control: American College of Endocrinology position statement on inpatient diabetes and metabolic control. Endocr Pract 2004, 10:77-82

5. NICE-SUGAR Study Investigators, Finfer S, Chittock DR, Su SY, Blair D, Foster D, Dhingra V, Bellomo R, Cook D, Dodek P, Henderson WR, Hébert PC, Heritier S, Heyland DK, McArthur C, McDonald E, Mitchell I, Myburgh JA, Norton R, Potter J, Robinson BG, Ronco JJ: Intensive versus conventional glucose control in critically ill patients. N Engl J Med 2009, 360:1283-1297.

6. Qaseem A, Humphrey LL, Chou R, Snow V, Shekelle P: Use of intensive insulin therapy for the management of glycemic control in hospitalized patients: a clinical practice guideline from the American College of Physicians. Ann Intern Med 2011, 154:260-267.

7. Meyfroidt G, Keenan DM, Wang X, Wouters PJ, Veldhuis JD, Van den Berghe G Dynamic characteristics of blood glucose time series during the course of critical illness: effects of intensive insulin therapy and relative association with mortality. Crit Care Med 2010, 38:1021-1029.

8. NICE-SUGAR Study Investigators, Finfer S, Liu B, Chittock DR, Norton R, Myburgh JA, McArthur C, Mitchell I, Foster D, Dhingra V, Henderson WR, Ronco JJ, Bellomo R, Cook D, McDonald E, Dodek P, Hébert PC, Heyland DK, Robinson BG: Hypoglycemia and risk of death in critically ill patients. NEngl J Med 2012, 367:1108-1118.

9. Krinsley JS, Grover A: Severe hypoglycemia in critically ill patients: risk factors and outcomes. Crit Care Med 2007, 35:2262-2267.

10. Hermanides J, Bosman RJ, Vriesendorp TM, Dotsch R, Rosendaal FR, Zandstra DF, Hoekstra JB, DeVries JH: Hypoglycemia is associated with intensive care unit mortality. Crit Care Med 2010, 38:1430-1434.

11. Krinsley JS, Schultz MJ, Spronk PE, Harmsen RE, van Braam Houckgeest F, van der Sluijs JP, Melot C, Preiser JC: Mild hypoglycemia is independently associated with increased mortality in the critically ill. Crit Care 2011, 15:R173.

12. Egi M, Bellomo R, Stachowski E, French CJ, Hart G: Variability of blood glucose concentration and short-term mortality in critically ill patients. Anesthesiology 2006, 105:244-252.

13. Krinsley JS: Glycemic variability: a strong independent predictor of mortality in critically ill patients. Crit Care Med 2008, 36:3008-3013.

14. Hermanides J, Vriesendorp TM, Bosman RJ, Zandstra DF, Hoekstra JB, Devries $\mathrm{JH}$ : Glucose variability is associated with intensive care unit mortality. Crit Care Med 2010, 38:838-842.

15. Krinsley JS, Meyfroidt G, van den Berghe G, Egi M, Bellomo R: The impact of premorbid diabetic status on the relationship between the 3 domains of glycemic control and mortality in critically ill patients. Curr Opin Clin Nutr Metab Care 2012, 15:151-160.

16. Egi M, Bellomo R, Stachowski E, French CJ, Hart GK, Taori G, Hegarty C, Bailey $M$ : The interaction of chronic and acute glycemia with mortality in critically ill patients with diabetes. Crit Care Med 2011, 39:105-111.

17. Finfer S, Wernermann J, Preiser JC, Cass T, Desavle T, Hovorka R, Joseph الر, Kosiborod M, Krinsley J, Mackenzie I, Mesotten D, Schultz M, Scott MG, Slingerland $R$, Van den Berghe $G$, Van Herpe T: Consensus recommendations on 'Measurement of blood glucose and reporting glycemic control in critically ill adults.' Crit Care 2013, in press.

18. Joseph II, Hipszer B, Mraovic B, Chervoneva I, Joseph M, Grunwald Z: Clinical need for continuous glucose monitoring in the hospital. J Diabetes Sci Technol 2009, 3:1309-1318.

\section{doi:10.1186/cc12584}

Cite this article as: Krinsley JS: Glycemic control in the critically ill -

3 domains and diabetic status means one size does not fit all! Critical Care 2013, 17:131 